\title{
Empirical Investigation of Ripple Effect of Textile Industry in Guangdong Province on the Basis of Input-Output
}

\author{
An LU, Jing ZHU* and Shan SUO \\ School of Business, Beijing Institute of Fashion Technology, Beijing, China \\ ${ }^{*}$ Corresponding Author
}

Keywords: Textile Industry; Input-Output; Ripple Effect; Intermediate Demand Rate; Intermediate Input Rate; Induction Coefficient; Influence Coefficient.

\begin{abstract}
In view of the slow growth of the textile industry in Guangdong Province, this article analyzes the development and ripple effect of textile industry on the basis of input-output of Guangdong Province in 2015. By analyzing the intermediate demand rate and the intermediate input rate, the textile industry has the nature of raw material industry and the added-value rate is low. Through measuring the influence coefficient and the induction coefficient, it can be concluded that the textile industry has a higher driving force for social production than the social average. However, other industries are not strong enough incentive to the increase of the production of textile industry in Guangdong.
\end{abstract}

\section{Introduction}

The textile industry is not only a traditional manufacturing sector in China, but also an important sector of export of China. It has played a huge role in developing the national economy, solving employment problems and increasing foreign exchange reserves. In the past four decades of reform and opening up, the textile and garment industry in Guangdong has continued to develop and has formed a cluster of textile and garment industries. The textile and garment industry has become one of the nine most influential pillar industries in this province. Guangdong has gradually evolved from a backward agricultural province to a major manufacturing and a well-known economic province in China. However, there are a series of problems of textile industry, such as slow growth of total output, low added-value rate and declining of significance in national economy in recent years. Therefore, it is necessary to clarify the status of operation of the textile industry and the degree of relevance with other industries. Based on the input-output analysis method, this article empirically studies the ripple effect of the textile industry by using the input-output table of Guangdong Province in 2015, it concludes the degree of association between the textile industry and other industrial sectors and the interaction with other industries. This article provides a reference for the overall development and optimization of the textile industry in Guangdong.

\section{Overview of the Development of Textile Industry in Guangdong Province}

\subsection{Coverage of the Textile Industry}

According to GB/T 4754-2017 "National Economic Industry Classification", the textile industry belongs to the 17th category under the C-class manufacturing industry in the "National Economic Industry Classification", it includes 8 sub-categories. There is a clear distinction between the textile and garment industry. As shown in Table 1 for details. [1] The research and analysis of this article are all about the 17th category of textile industry, and do not involve 18 or 19 categories.

\subsection{The Total Output and Growth Rate of the Textile Industry in Guangdong Province}

The total output and growth rate of the textile industry in Guangdong from 2005 to 2015 is shown in Figure 1. The total output growth of textile industry has been flat in the past decade, and continued to grow in 2005-2010. The output in 2010-2012 decreased by 61.97 billion yuan. The year-on-year decrease was $19.54 \%$, and the output increased with a growth rate of $34.48 \%$ in 2015 . 
Table 1. China's National Economic Industry Classification and Code

\begin{tabular}{ll|ll}
\hline code & classification name & code & classification name \\
\hline $\mathrm{C} \quad$ manufacturing & 18 & Textile and garment, clothing industry \\
\hline 17 & Textile industry & 181 & Woven garment manufacturing \\
\hline 171 & $\begin{array}{l}\text { Cotton textile and printing, dyeing } \\
\text { finishing }\end{array}$ & 182 & $\begin{array}{l}\text { Knitted or crocheted garment } \\
\text { manufacturing }\end{array}$ \\
\hline 172 & Wool textile and dyeing, finishing & 183 & Clothing manufacturing \\
\hline 173 & Hemp textile and dyeing, finishing & 19 & $\begin{array}{l}\text { Leather, fur, feathers and their products } \\
\text { and footwear }\end{array}$ \\
\hline 174 & Silk textile and printing, finishing & 191 & Leather processing \\
\hline 175 & $\begin{array}{l}\text { Chemical fiber weaving and printing, } \\
\text { dyeing finishing }\end{array}$ & 192 & Leather goods manufacturing \\
\hline 176 & $\begin{array}{l}\text { Manufacture of knitted or crocheted } \\
\text { fabrics, their products }\end{array}$ & 193 & Fur tanning and product processing \\
\hline 177 & Home textile manufacturing & 194 & $\begin{array}{l}\text { Feather (velvet) processing and product } \\
\text { manufacturing }\end{array}$ \\
\hline 178 & $\begin{array}{l}\text { Industrial textile finished products } \\
\text { manufacturing }\end{array}$ & 195 & Footwear industry \\
\hline
\end{tabular}

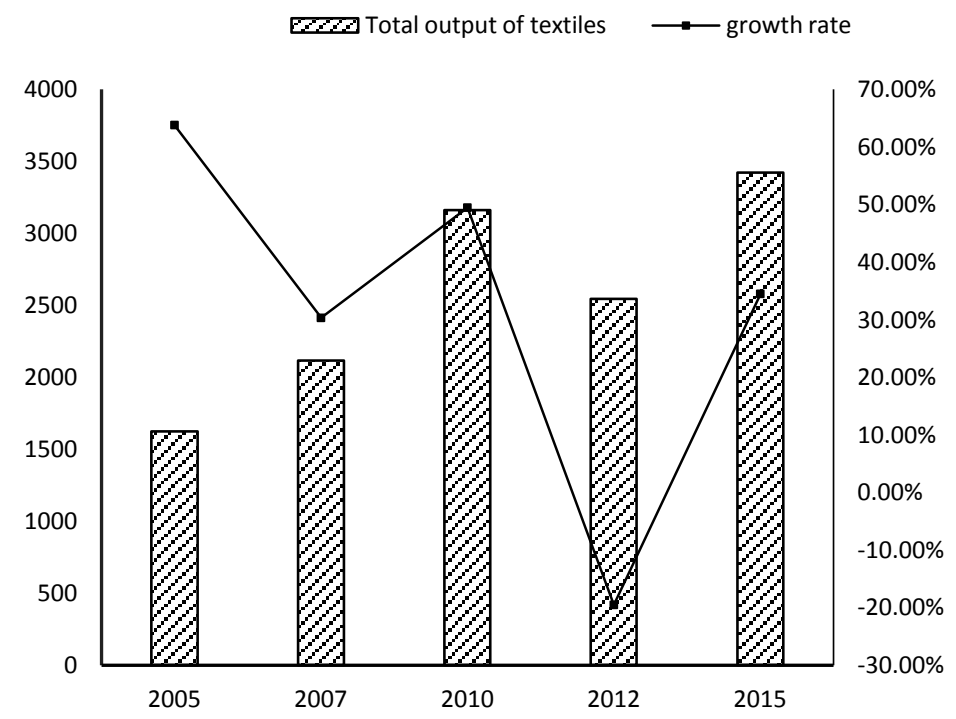

Figure 1. 2005-2015 Total Output and Growth Rate of Textile Industry in Guangdong Province

The total output of Guangdong textile industry and garment industry from 2005 to 2015 is shown in Figure 2. According to the comparison of numerical values, it can be found that the gap between textile industry and garment industry is small in 2005. While as of 2015 , the figure of the total output of garment industry is higher than textile industry and the figure of garment industry is close to twice that of the textile industry. The textile industry has flourished in the past decade, but the textile industry has developed slowly.

From the ratio of the textile industry, the garment industry, the total of textile industry and the garment industry to the GDP of Guangdong Province shown in Figure 3, it can be seen that the change of the status of the above-mentioned industries in Guangdong's national economy. The ratio of the total output of the textile and garment industry has remained above $15 \%$ in $2005-2010$, but the proportion has been decreasing since 2010. The proportion of textile industry in the total industry is much lower than the garment industry. This shows that the importance of the textile industry in the development of the national economy has been continuously reduced in Guangdong. 


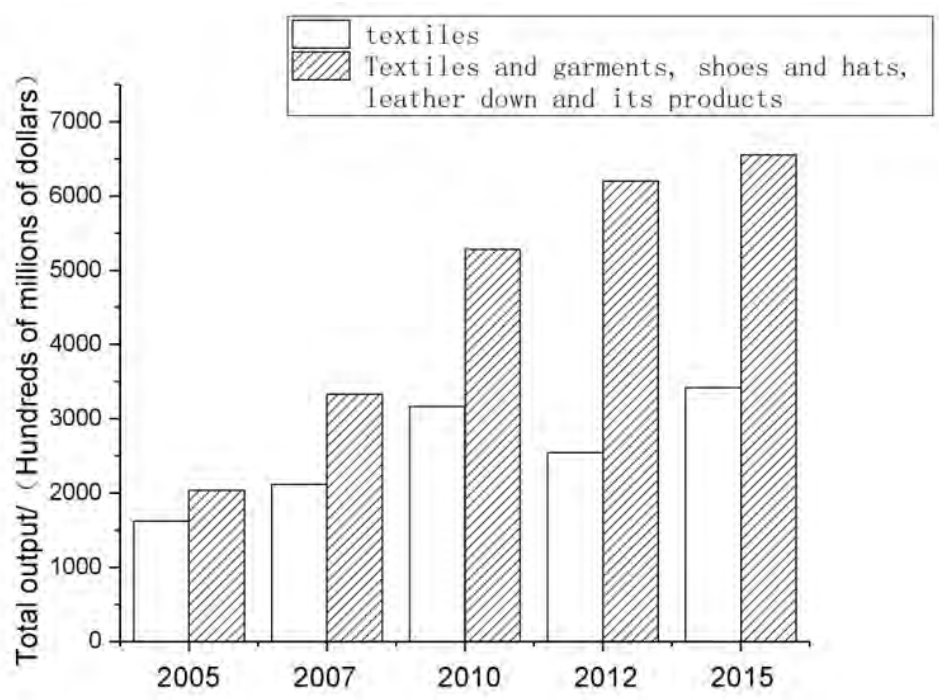

Figure 2. 2005-2015 Textile and Textile Garment Shoes, Hats Leather down, its Products Total output in Guangdong Province

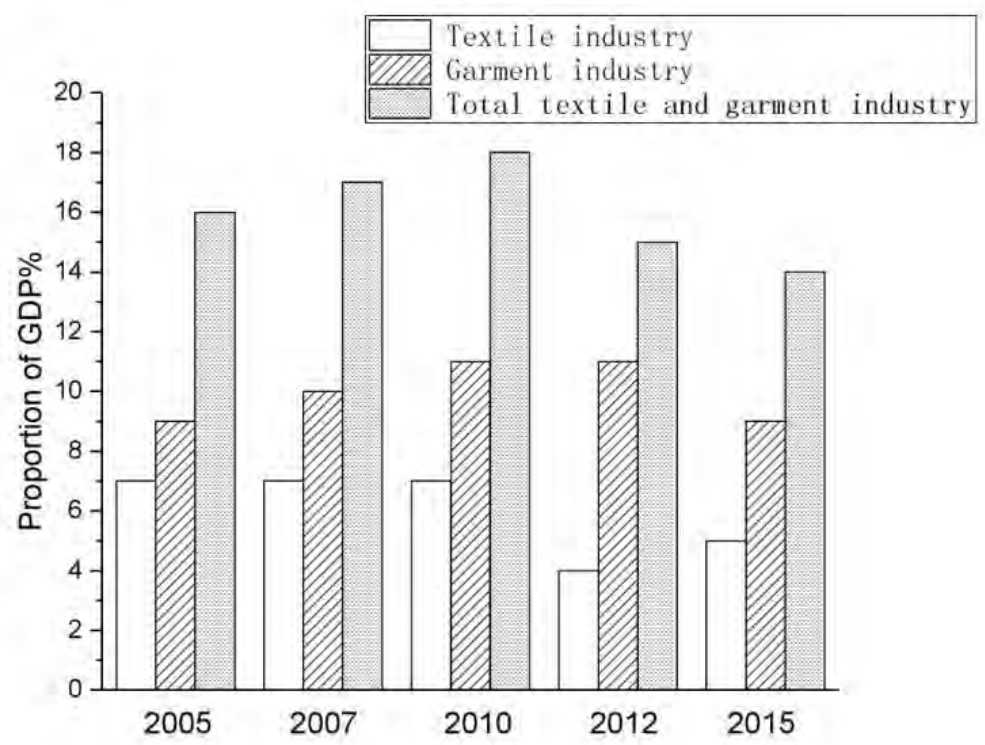

Figure 3. 2005-2015 Textile Industry, Garment Industry, Total Textile and Garment Industry Accounts for GDP in Guangdong Province

\section{Textile Industry Ripple Effect Analysis Indicators and Data Sources}

Industrial linkage refers to the relationship between an industry and other sectors of the industry, and there are different contacts between different industries. Ripple effect of textile industry means that when the textile industry sector changes, according to different industry linkages, causing changes in other relevant industrial sectors, these changes will be transmitted in turn, and continue to affect the changes of other related industries.[2]

The study of the ripple effect of the textile industry can determine the different industry linkages by calculating the intermediate demand rate and the intermediate input rate through the input-output table. As a result, the research on the ripple effect of the textile industry can be realized, when analyzing the degree of interaction between the textile industry and other industrial sectors including the influence coefficient and the sensitivity coefficient.

\subsection{Four Analytical Indicators of the Ripple Effect of the Textile Industry}

The intermediate demand rate and the intermediate input rate are two indicators that reflect the 
interlinkages and interdependence of various industrial sectors.

The intermediate demand rate refers to the ratio of the intermediate demand of each industrial sector to the total demand of the industrial sector. Its calculation formula is:

$$
\mathrm{G}_{\mathrm{i}}=\frac{\sum_{\mathrm{j}=1}^{\mathrm{n}} \mathrm{X}_{\mathrm{ij}}}{\sum_{\mathrm{j}=1}^{\mathrm{n}} \mathrm{X}_{\mathrm{ij}}+\mathrm{Y}_{\mathrm{i}}} \quad(\mathrm{i}=1,2, \ldots, n)
$$

$\mathrm{G}_{\mathrm{i}}$ represents the intermediate demand rate of the i-th industry sector;

$\sum_{\mathrm{j}=1}^{\mathrm{n}} \mathrm{X}_{\mathrm{ij}}$ represents the sum of the intermediate demands of the industrial sectors for the products of the i-th industrial sector;;

$\sum_{j=1}^{n} X_{i j}+Y_{i}$ represents the total output of the products of the $i$-th industrial sector;

$Y_{i}$ represents the final demand component of the i-industry sector products.

The intermediate input rate of an industrial sector refers to the ratio of the intermediate input to the total input in the production process for a certain period of time (usually one year). Its calculation formula is:

$$
F_{j}=\frac{\sum_{i=1}^{n} X_{i j}}{\sum_{i=1}^{n} X_{i j}+D_{j}+N_{j}} \quad(j=1,2, \ldots, n)
$$

$\mathrm{Fj}$ represents the intermediate input rate of the $\mathrm{j}$ industrial sector; $\mathrm{D}_{\mathrm{j}}$ represents the full depreciation expense of the $\mathrm{jth}$ industrial sector (one year); $\mathrm{N}_{\mathrm{j}}$ represents the value created by the $\mathrm{jth}$ industrial sector.

According to the ratio of different intermediate demand rates and intermediate input rates of each industries, the industrial structure can be divided into four categories, namely: intermediate product-type basic industry sector, intermediate product-type industrial sector, final demand-type industrial sector, and final demand-type basic industry sector. [3] The influence coefficient of the textile industry refers to the degree of production input in other related industries caused by each unit of final product produced in textile industry. It measures the driving force of an industry to social production and can be used to reflect the backward linkages of the industry. [4] The induction coefficient of the textile industry refers to the output of the textile industry requested by the production of other industries for each additional unit of final application in the national economy. It measures the extent to which the textile industry is affected by other industries, and can be used to describe the extent of industry forward linkages. The calculation formulas are:

$$
\begin{aligned}
& e_{j}=\frac{\sum_{i=1}^{n} c_{i j}}{\frac{i}{n} \sum_{i=1}^{n} \sum_{j=1}^{n} C_{i j}} \quad(i, j=1,2, \ldots, n) \\
& e_{i}=\frac{\sum_{j=1}^{n} C_{i j}}{\frac{1}{n} \sum_{i=1}^{n} \sum_{j=1}^{n} C_{i j}} \quad(i, j=1,2, \ldots, n)
\end{aligned}
$$

$e_{j}$ is the influence coefficient of the $j$-th industry, $e_{i}$ is the induction coefficient of the $i$-th industry; respectively, $\mathrm{i}, \mathrm{j}$ represent the horizontal and vertical columns, $\mathrm{n}$ is the number of industrial sectors; $\mathrm{C}_{\mathrm{ij}}$ is the element in the inverse coefficient inverse coefficient table $\mathrm{C}(\mathrm{i}, \mathrm{j}=1,2, \ldots \mathrm{n})$.

According to the calculation result of the formula, if $e_{j}>1$, it means that the influence of the industrial sector is above the average level in the whole industry; if $e_{j}=1$, it means that the influence of the industrial sector is average in the whole industry; If $e_{j}<1$, it means that the influence of the industrial sector is at a downstream level throughout the industry. Similarly, $\mathrm{e}_{\mathrm{i}}$ can 
also make a similar explanation.

\subsection{Description of Data Related to the Impact of the Textile Industry}

Since the input-output table is updated every five years, the 2015 input-output table is the latest one currently released by Guangdong Province. According to the 2015 Guangdong Input-Output Table, the intermediate demand rate, the intermediate input rate, the influence coefficient, and the induction coefficient of each industrial sector can be calculated accurately.

\section{Empirical Results and Analysis of the Effect of Textile Industry in Guangdong Province}

Table 2. Empirical Results of the Ripple Effect of the Textile Industry

\begin{tabular}{lll}
\hline & textile industry & Rank in 42 sectors \\
\hline Intermediate demand rate & 0.8762 & 12 \\
Intermediate input rate & 0.8124 & 6 \\
Influence coefficient & 1.1529 & 17 \\
Induction coefficient & 0.6988 & 26 \\
\hline
\end{tabular}

The empirical results of ripple effect of the textile industry are shown in Table 2. From the analysis of the ways and degrees of industrial linkages, the intermediate demand rate of the textile industry reflects the ratio between, the amount in each unit of the textile product which is used as raw material of other industry sectors, and the total output of each unit of the textiles. Since there is an equation of 'intermediate demand rate + final demand rate $=1$ ', the higher the intermediate demand rate of an industrial sector and the lower the final demand rate, the sector has the nature of the raw material industry; otherwise, it has the nature of providing the final product. The intermediate demand rate of the textile industry is 0.8762 , ranking 12 th among the 42 national economic sectors, in the top $1 / 3$ position, and the intermediate demand rate is relatively large, so that the textile industry in Guangdong has the nature of raw material industry.

The intermediate input rate in the production process of the textile industry reflects, in order to meet its own production needs, the proportion of textiles from other industry sectors used as raw materials in the production of one unit of textiles. Since 'the total investment in the textile industry = intermediate input of textile + depreciation + added-value = total output of the textile industry', 'the added-value rate of the textile industry = added-value / total output', and there is 'added-value rate + intermediate input rate $=1$ '. Therefore, if the intermediate input rate of the textile industry is higher, the added-value rate will be lower. It can be seen from Table 2 that the intermediate input rate of the textile industry in Guangdong is 0.8124 , ranking 6th among the 42 sectors of the national economy and in the forefront of the national economic sector. The intermediate input rate is very high, so it means the textile industry in Guangdong is a high intermediate input rate and low value-added rate industry.

Table 3. Schematic Diagram of Industrial Three-Dimensional Structure

\begin{tabular}{lll}
\hline & Small intermediate demand & Large intermediate demand \\
\hline Large intermediate & III Final demand-type Industry & II Intermediate product-type industry \\
input & Sector & sector \\
Small intermediate & IV Final demand-type basic & I Intermediate product-type basic \\
input & industry sector & industry sector \\
\hline
\end{tabular}

According to the three-dimensional structure diagram of the industry shown in Table 3 , the textile industry belongs to the intermediate product-type industrial sector with large intermediate demand and large intermediate input.

From the perspective of the ripple effect of the textile industry or the interaction between the textile industry and other industrial sectors, assuming that the influence coefficient of the textile industry is greater than 1 , it means that the production of the industry has a greater degree of 
influence on the production of other industrial sectors than the influence of social average. The greater the influence coefficient, means the growth of the demand for this final product can have greater incentive on the total growth of the social manufacture. From Table 3, it can be seen that the influence coefficient of the textile industry is 1.1529 , the influence coefficient of the textile industry is greater than 1 and it is in the top $40 \%$ of the 42 industries in this province. This can indicate, both the influence of the textile industry in Guangdong, and the capacity of it the output of other industries for each unit of textile products, are higher than the average level across the whole sectors of industries in the society. Also the ripple effect of the demand for social production and the driving force for production are strong. [5]

Assuming that the textile's induction coefficient is greater than 1, it means that for each additional unit of the national economy, the output of the textile industry for other sectors needs to be higher than the social average. The greater the induction coefficient indicates that the demand of department for economic development is more sensitive, and vice versa. [6] The induction coefficient of the textile industry is 0.6988 . It can be seen that the textile industry's induction coefficient is less than 1 and it is in the 26th position of the middle and middle reaches of 42 industries in Guangdong Province. It indicates that the textile industry has a lower driving force for the national economy than the social average and the improvement of the national economic has little impact on the production demands for the textile industry.

\section{Conclusion}

In the textile industry of Guangdong Province, the growth of total output was slow during 2005-2015, and the overall trend of its weight in GDP in Guangdong decreased and was lower than that of the garment industry. This shows the influence of the textile industry on the development of Guangdong's national economy is weakening. According to the analysis of the influence effect of the textile industry, the textile industry in Guangdong is an intermediate product-type basis industrial sector, which has the nature of raw material industry and low added-value rate, and it has a low degree of forward linkage, that means the impact of the improvement of other industries' production is relatively small on the textile industry. On the other hand, the textile industry has a high degree of demand for social production, which can effectively stimulate the production of other industrial sectors. It is an industry that may bring higher returns once it is supported by the government. Therefore, the government should increase the emphasis on the industry and formulate relevant preferential policies to ensure the rapid development of the textile industry in the future. At the same time, the textile industry should accelerate the optimization and upgrading of the industrial structure as much as possible, attach importance to professional talent training, technology development, design and other high added value links, increase the added value of the industry, and realize the transformation of the industrial structure, that is, from the intermediate product-type industrial sector to the Intermediate product-type basic industry sector.

\section{Acknowledgement}

Project Fund: Countermeasures for the transfer of China's textile and garment industry under the 'One Belt, One Road' strategy of the Beijing Municipal Education Commission's Social Science Program (Project No.: AJ2016-24).

Support plan for the construction of Beijing high-level faculty in Colleges and Universities and Youth Top-notch talent Training Project (Project No.: CIT\&TCD201804048).

\section{References}

[1] You Qian, Lu An. Research on the development of China's textile and garment industry based on input-output analysis [A]. Woolen Textile Technology, 2018, 46 (1): 73-77.

[2] Lu An, Hao Shuli. Garment Industry Organization [M]. Beijing: People's Publishing House, 
2013.

[3] Li Mingjie, Lu An. Research on the development of textile manufacturing industry in Zhejiang Province based on input-output analysis [A]. Woolen Textile Technology, 2018, 46 (3): 79-84.

[4] Lin Shilian. Research on the Influence of Input-output Method on the Related Industries of Guangdong Education Industry [J]. Industry Analysis, 2016 (4): 50-56.

[5] Zhang Jianlei, Chen Yujie, Liu Yunying, Cheng Longzhen. Industrial Correlation and Industry Spread of Xinjiang Textile Industry [A]. Silk, 2018, 55 (8): 60-67.

[6] Chang Lina, Zhuo Xiaosu. An Empirical Analysis of the Influence of China's Textile Industry-Based on the Input-Output Method [J]. Journal of Shanxi Normal University (Social Science Edition). 2009 (S2). 